\title{
Rupture process of the 2005 West Off Fukuoka Prefecture earthquake obtained from strong motion data of K-NET and KiK-net
}

\author{
Haruko Sekiguchi ${ }^{1}$, Shin Aoi ${ }^{2}$, Ryou Honda $^{3}$, Nobuyuki Morikawa ${ }^{2}$, Takashi Kunugi ${ }^{2}$, and Hiroyuki Fujiwara ${ }^{2}$ \\ ${ }^{1}$ Active Fault Research Center, GSJ, National Institute of Advanced Industrial Science and Technology, \\ 1-1-1 Higashi, Tsukuba, Ibaraki, 305-8567 Japan \\ ${ }^{2}$ National Research Institute for Earth Science and Disaster Prevention 3-1 Tennodai, Tsukuba, Ibaraki, 305-0006 Japan \\ ${ }^{3}$ Hot Springs Research Institute of Kanagawa Prefecture 586 Iriuda, Odawara, Kanagawa, 250-0031, Japan
}

(Received September 5, 2005; Revised December 8, 2005; Accepted December 12, 2005; Online published January 27, 2006)

\begin{abstract}
We have investigated the rupture process of the 2005 West Off Fukuoka Prefecture earthquake by the multitime-window linear waveform inversion method using the strong ground motion data recorded at 11 K-NET and KiK-net stations. From the waveforms of the $P$-wave portion, it is indicated that the energy release in the first few seconds was markedly lower than the subsequent part, and this causes difficulty in identifying onset of the $S$-wave. To decide an appropriate time window for the waveform inversion, we estimate the $S$-wave onset using aftershock records. The inverted slip distribution shows a single asperity of $8 \mathrm{~km} \times 6 \mathrm{~km}$ and its center located 8 $\mathrm{km}$ to the southeast and $6 \mathrm{~km}$ above the hypocenter. The asperity explains most of the large-amplitude signals in the observed waveforms. The turning point from the initial low-energy-release rupture to the main high-energyrelease rupture is estimated from the spatial variation of the observed initial rupture phase. It is found $3.3 \mathrm{~s}$ after the initiation of the rupture at about $4 \mathrm{~km}$ to the southeast of the hypocenter. Stress drop during the initial rupture is estimated to be in the same order of those of moderate size aftershocks, which indicates that the initial rupture is an ordinary dynamic rupture.
\end{abstract}

Key words: The 2005 West Off Fukuoka Prefecture earthquake, rupture process, strong motion, K-NET, KiKnet.

\section{Introduction}

On 20 March 2005 at 10:53 (JST), the 2005 West Off Fukuoka Prefecture earthquake $\left(33.7402^{\circ} \mathrm{N}, 130.1722^{\circ} \mathrm{E}\right.$, $9.84 \mathrm{~km}, \mathrm{Mw} 6.9$; manual hypocenter determination from Hi-net data (High-sensitivity seismograph network; Obara et al., 2005)) occurred beneath Genkai Nada (Sea of Genkai) about $25 \mathrm{~km}$ to the northwest of Fukuoka City and struck the northern part of Kyushu, western Japan. This earthquake was a left-lateral strike slip according to the fault mechanism determined from the $P$-wave first motion direction obtained by Hi-net and the moment tensor solution by F-net (Full range seismograph network of Japan; Fukuyama et al., 1996) (Fig. 1). Aftershocks extended bilaterally in the NW-SE direction, consistent with these mechanisms.

Many active faults running in the NW-SE direction are mapped around the source area on land (Karakida et al., 1994). On the seabed, the Japan Coast Guard has found an active fault running parallel to the aftershock distribution of 2005 earthquake at about $5 \mathrm{~km}$ offset. In the source area of this earthquake, no clear active fault trace has been identified. In the source area, in 1985, has found only a short segment of sloping seabed that may be related to faulting, but they did not discover any extension of the step (Geological Survey Japan, 2005b). After the earthquake,

Copyright (c) The Society of Geomagnetism and Earth, Planetary and Space Sciences (SGEPSS); The Seismological Society of Japan; The Volcanological Society of Japan; The Geodetic Society of Japan; The Japanese Society for Planetary Sciences; TERRAPUB sonic prospecting was conducted by the Japan Coast Guard in the area over the 2005 sequence (Japan Coast Guard, 2005). So far, they have found no surface ruptures.

Peak ground velocities (PGV) of 5-60 cm/s were observed at K-NET (Kinoshita, 1998) and KiK-net (Aoi et al., 2000) stations within $50 \mathrm{~km}$ of the epicenter. The highest PGV among all the K-NET and KiK-net stations was $63.8 \mathrm{~cm} / \mathrm{s}$, observed at FKO006 in Fukuoka City. In the observed waveforms at stations close to the epicenter, we can see two unique features: 1) the first few seconds of the $P$-wave had much smaller amplitude than the following $P$-wave part (Fig. 2); and 2) the large-amplitude $S$-wave started with an approximately $1 \mathrm{~s}$-wide pulse, immediately followed by a long-period wave. The $1 \mathrm{~s}$ pulse, which looks like the $S$-wave onset phase, is demonstrably too late to be $S$-wave onset referring to theoretical travel time. The true $S$-wave onset must be a few seconds before the $1 \mathrm{~s}$ pulse. Hereinafter, we call the first few seconds of small amplitude in the waveforms the "initial rupture phase" and the corresponding low energy release rupture the "initial rupture"; and the following larger amplitude in the waveforms the "main rupture phase" and the corresponding rupture the "main rupture". Several studies have reported that the weak initial phases are generally observed for earthquakes in a wide magnitude range (e.g., Beroza and Ellsworth, 1996; Mori and Kanamori, 1996). This phenomenon is explained by two ways; 1) it is the last stage of the aseismic pre-slip accelerating to unstable dynamic rupture (different from ordinary coseismic rupture), or 2) it is an accumulation of in- 


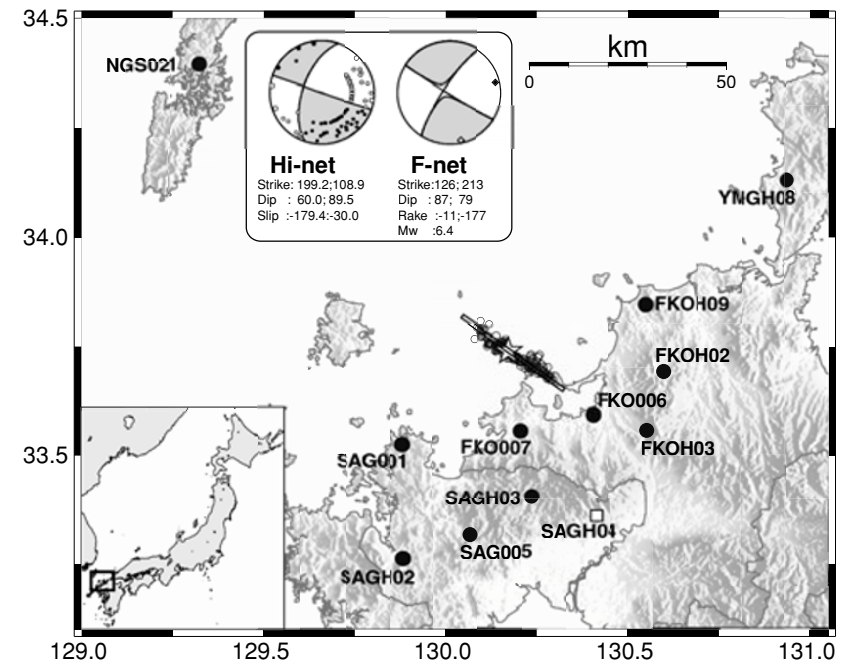

Fig. 1. The observation stations used for the waveform inversion and the fault plane model. Closed circles show the strong-motion stations used in the waveform inversion analysis. The open rectangle is the station whose waveforms are shown in Fig. 3. The star indicates the epicenter of the mainshock. Open circles are aftershock epicenters within 24 hours of the main shock, located by Hi-net epicenter determination system. A narrow rectangle in the aftershock distribution illustrates the margin of the fault plane model on to the surface. Among the KiK-net stations, records on the surface are used for station $\mathrm{FKOH02}$ and records at the down-hole are used for the other stations.

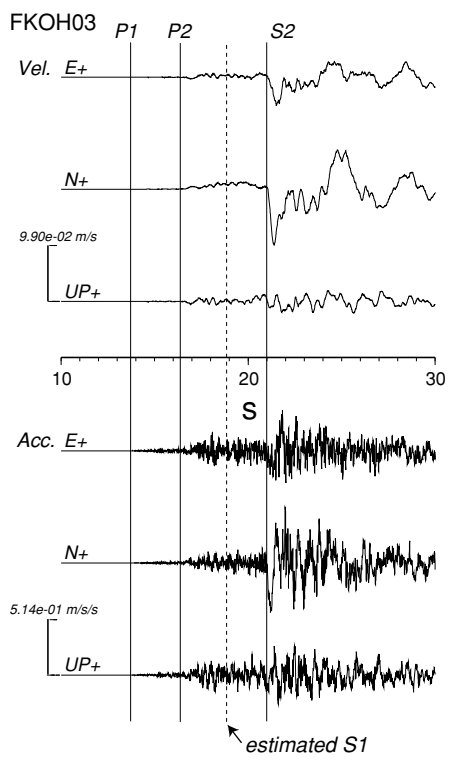

Fig. 2. "Initial rupture phase" and "main rupture phase" seen on observed waveforms at station FKOH03. $P 1$ is the $P$-wave onset of the initial rupture phase. $P 2$ and $S 2$ are the $P$ and $S$-wave onset of main rupture phase. The $S$-wave onset of initial rupture phase, $S 1$, is estimated by theoretical $S$ - $P$ time. It is hard to identify $S 1$ by eye.

creasingly large subevents of unstable dynamic rupture (ordinary coseismic rupture).

In this paper, we estimate the rupture process by means of waveform inversion analysis. Before the inversion analysis, we investigate the characteristics of the initial rupture phase and the main rupture phase. Since we find it difficult to identify $S$-wave onset by eye on the observed waveforms, we estimate it using the $S$ - $P$ time of aftershocks.

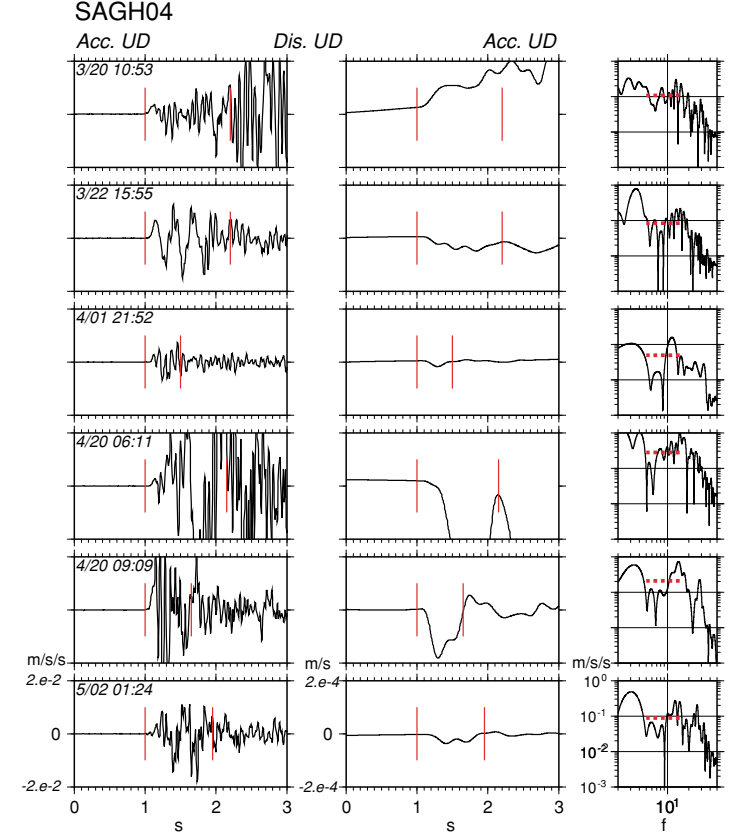

Fig. 3. Comparison of the initial part of the $P$-wave's "initial rupture phase" of the mainshock (top) with the $P$-wave portion of aftershocks (Table 1) (below top). Left: Acceleration waveforms, Center: Displacement waveforms, and Right: Acceleration spectra of UD component. Time of each earthquake is indicated at the top left corner of the windows in the left column. Waveforms are aligned so that the $P$-wave onset comes at $1 \mathrm{~s}$. The fourier transform of acceleration and integration of displacement waveforms (see article) are done for the time windows denoted by two vertical red lines on waveforms. Flat level (red dashed lines) are obtained by taking average in $5-15 \mathrm{~Hz}$ frequency range.

2. Initial Rupture Phase and Main Rupture Phase

The amplitudes of the initial rupture phase are quite small compared to those of the main rupture phase. For example, at station FKOH03 (Fig. 2), the average amplitudes of the $P$-wave initial rupture phase (from $P 1$ to $P 2$ ) are about 6 to 7 times (about 6 times for EW component and 7 times for NS and UD components) smaller than the average amplitude of the $P$-wave main rupture phase (from $P 2$ to estimated $S 1$ ) on acceleration waveforms; and this ratio rises to 10 to 30 times (about 16 times for EW component, 32 times for NS component and 11 times for UD component) on velocity waveforms. The average amplitudes of the $P$-wave main rupture phase are 1 to 3 times smaller than the average amplitude of the $S$-wave main rupture phases on the acceleration and velocity waveforms. Considering these amplitude ratios, we would expect the $S$-wave initial rupture phase to have much smaller amplitude than the $P$-wave main rupture phase. In fact, the amplitude maintains a similar level before and after the estimated onset of the $S$-wave initial rupture phase. The estimation of $S 1$ is explained in Section 3.3.

As we referred in Chapter 1, there is an argument whether the initial rupture is special and differs from ordinary coseismic rupture or not. In order to judge it, we compare in Fig. 3 the initial part of the $P$-wave signal of the mainshock and several aftershocks (Table 1, 3/22, 4/1, 4/20 6:11 and 9:09, and 5/2). Displacement waveforms of aftershocks are corrected for the difference of radiation pattern and geomet- 
Table 1. Source information of aftershocks (Hi-net manual hypocenter determination)

\begin{tabular}{cccccc}
\hline Date and time & Latitude & Longitude & Depth $(\mathrm{km})$ & $\mathrm{Mw}$ & $\Delta \sigma_{a} / \Delta \sigma_{m}$ \\
\hline 2005/03/21 06:17:00.646 & 33.7223 & 130.1923 & 10.38 & 4.4 & - \\
2005/03/22 15:55:33.532 & 33.7215 & 130.1782 & 8.59 & 5.3 & 0.6 \\
2005/03/24 23:38:43.003 & 33.7329 & 130.1782 & 9.46 & 4.2 & - \\
2005/04/01 21:52:13.644 & 33.6693 & 130.3204 & 13.11 & 4.8 & 1.8 \\
2005/04/20 06:11:26.964 & 33.6715 & 130.2944 & 14.42 & 6.2 & 1.2 \\
2005/04/20 09:09:43.014 & 33.6770 & 130.2877 & 13.22 & 5.4 & 2.3 \\
2005/05/02 01:23:57.724 & 33.6687 & 130.3214 & 12.35 & 5.0 & 1.1 \\
\hline
\end{tabular}

rical spreading relative to those of mainshock. Acceleration waveforms are corrected only for geometrical spreading relative to mainshock.

When the source spectrum follows $\omega^{2}$-decay model, high-frequency flat level of acceleration spectrum, $A$, is related to the low-frequency flat level of displacement spectrum, $\Omega(\omega \rightarrow 0)$, then to moment, $M_{o}$, as in the following,

$$
A=\omega_{c}^{2} \Omega(\omega \rightarrow 0)=\left(2 \pi \frac{v_{r}}{r}\right)^{2} \Omega(\omega \rightarrow 0) \propto \frac{v_{r}^{2}}{r^{2}} M_{o} .
$$

Here, $\omega_{c}$.is the angular corner frequency of the $\omega^{2}$-decay spectrum model, and rewritten as $\omega_{c}=2 \pi v_{r} / r$, where $v_{r}$. is rupture velocity and $r$ is the dimension of rupture area of an earthquake. Stress drop of a circular crack is evaluated in the following formula by Eshelby (1957),

$$
\triangle \sigma=\frac{7}{16} \frac{M_{o}}{r^{3}}
$$

From (1) and (2), we get,

$$
\triangle \sigma \propto \frac{7}{16} M_{o}^{-\frac{1}{2}} A^{\frac{3}{2}} v_{r}^{-3}
$$

We apply this relation to evaluate stress drop ratios of aftershocks listed in Table 1 to the initial rupture of mainshock. Here, we assume $v_{r}$ is similar for all these earthquakes. We evaluate relative value of $M_{o}$ by the integration of displacement waveform, $u(t)$, in a time range we are focused (from $t_{1}$ to $t_{2}$ ).

$$
M_{o} \propto \int_{t_{1}}^{t_{2}} u(t) d t
$$

Stress drop ratios of aftershocks to the initial rupture of mainshock, $\Delta \sigma_{a} / \Delta \sigma_{m}$, are listed in the rightmost column of Table 1. The value varies between 0.6 and 2.3. We can say that the stress drop of the initial rupture of mainshock and these aftershocks are in the same order, which suggests that the initial rupture of the mainshock may not differ from the dynamic rupture of small earthquakes.

The time differences between $P 1$ and $P 2$ vary slightly among stations, and the variation shows spatially systematic features: shorter at stations to the east of the source region and longer at stations to the north (Fig. 4). This suggests that the starting point for main rupture phase (Hypo2 ) was located to the east of the hypocenter (Hypo-1). We search for the Hypo-2 location relative to the Hypo-1 on the fault plane model given in the next section. The residuals between the observed $P 2-P 1$ time difference and the theoretically expected value are calculated and summed for a set

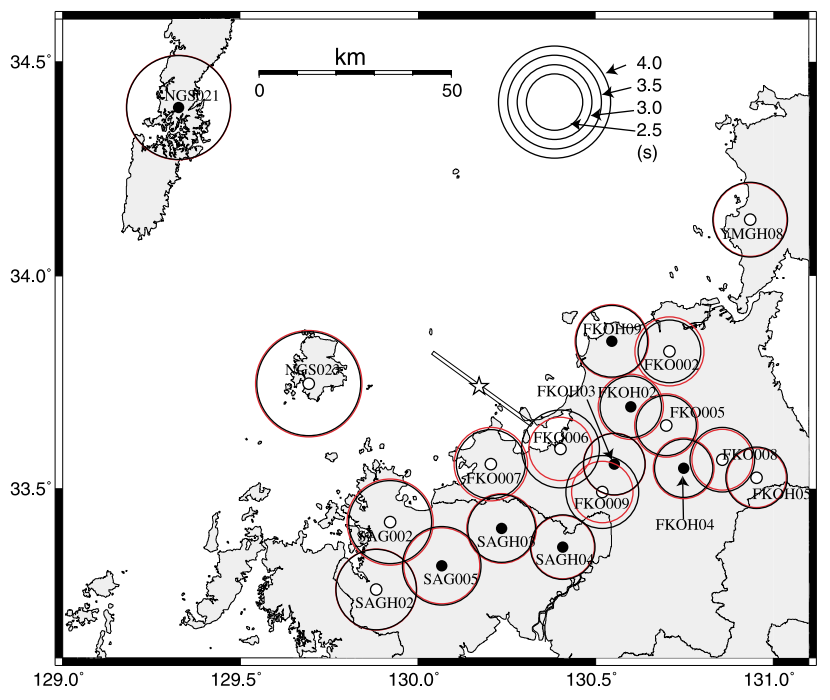

Fig. 4. Spatial variation of $P 2-P 1$ time difference. Black circles show the observed values. Red circles show the theoretically expected values when the Hypo-2 is located so that the difference between the observed and the theoretical values are minimized. Optimal location of Hypo-2 is shown in Figs. 5 and 6. Stations denoted by closed circle are used for grid search of Hypo-2. Stations denoted by open circle are not used in grid search because there are uncertainties in picking the main rupture phases.

of stations with clear $P 2$ onset (denoted by closed circle). The location and the time delay that minimize the summed residual are searched using a grid search at $1 \mathrm{~km}$ intervals in the strike and downdip directions and in $0.1 \mathrm{~s}$ intervals in time. It is found at $4 \mathrm{~km}$ to the southeast along the strike direction, $1 \mathrm{~km}$ in the downdip direction from Hypo-1 and $3.3 \mathrm{~s}$ after the rupture initiation at Hypo-1. Figure 5 shows the distribution of residual per station (summed residual divided by the number of stations used) when Hypo-2 is assumed at each point on the fault plane $3.3 \mathrm{~s}$ after the rupture initiation at Hypo-1. The contours are elongated in vertical direction, which means that location of Hypo-2 has larger uncertainty in vertical direction than in horizontal direction. The minimum of the per-station residual is 0.046 s. This residual value is quite small considering the uncertainty of picking the main rupture phase (about $\pm 0.1 \mathrm{~s}$ at stations with clear $P 2$ onset). Projecting this picking uncertainty on to the distribution of per-station residual, error bars about the location of Hypo- 2 extend about $\pm 1.5 \mathrm{~km}$ in along-strike direction, about $\pm 4.5 \mathrm{~km}$ in along-dip direction and about $+0.1 \mathrm{~s}$ and $-0.2 \mathrm{~s}$ in along-time direction.

The location of Hypo-2 relative to Hypo-1 is also deter- 


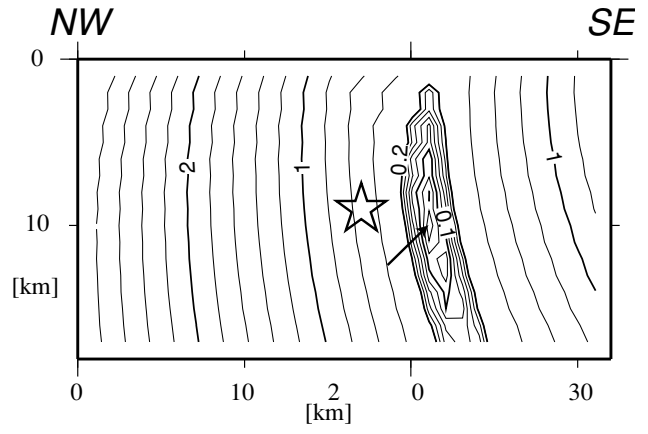

Fig. 5. Distribution of per-station residual (unit: $s$ ) between the observed $P$ 2- $P 1$ time difference and the theoretically expected value when Hypo-2 is assumed at each point over the fault plane triggered $3.3 \mathrm{~s}$ after the rupture initiation at Hypo- 1 . The contours are drawn at $0.02 \mathrm{~s}$ intervals up to value of $0.2 \mathrm{~s}$ and at $0.2 \mathrm{~s}$ intervals beyond $0.2 \mathrm{~s}$. The minimum of the per-station residual is $0.046 \mathrm{~s}$ when the Hypo-2 is located $4 \mathrm{~km}$ to the southeast in the strike direction and $1 \mathrm{~km}$ in the downdip direction (pointed by an arrow).

Table 2. Depth of bedrock assumed for strong motion stations used for the waveform inversion, given from PS-logging data at K-NET and KiK-net station distributed on the NIED web page, or estimated through modeling aftershock records.

\begin{tabular}{cc}
\hline Station code & Bedrock depth $(\mathrm{m})$ \\
\hline FKO006 & 600 \\
FKO007 & 300 \\
NGS021 & 0 \\
SAG001 & 0 \\
SAG005 & 0 \\
FKOH02 & 0 \\
FKOH03 & 0 \\
FKOH09 & 200 \\
SAGH02 & 0 \\
SAGH03 & 0 \\
YMGH08 & 0 \\
\hline
\end{tabular}

mined by Horikawa (2006) and Takenaka et al. (2006) by grid searching. Horizontal locations of Hypo-2 obtained by the three studies are close to one another. But the vertical locations are scattered; Horikawa (2006) and our study found Hypo-2 deeper than the Hypo-1, and Takenaka et al. (2006) found Hypo-2 shallower than Hypo-1. This would be due to the higher uncertainty of vertical location.

\section{Waveform Inversion for Rupture Process 3.1 Fault plane model}

We construct a fault model for our waveform inversion analysis to obtain the rupture process. The fault size is assumed to be $32 \times 18 \mathrm{~km}$ to cover aftershock distribution within 24 hours of the main shock (Fig. 1). We assume $\mathrm{N} 126^{\circ} \mathrm{E}$ and $87^{\circ}$ as the strike and dip angles, respectively, referring to the moment tensor solution of F-net (Fig. 1). The rupture starting point is located at the hypocenter determined by Hi-net: $33.7402^{\circ} \mathrm{N}, 130.1722^{\circ} \mathrm{E}, 9.84 \mathrm{~km}$.

\subsection{Velocity structure model}

Not much information is available about underground velocity structure around the source area. We use a crust and upper mantle model (the lowest $S$-wave velocity is $3.26 \mathrm{~km} / \mathrm{s}$ ) proposed by Ukawa et al. (1984) as our base model. Bedrock depth at each station is first assumed refer-
Table 3. Orientation of "North" of seismometer measured by Morikawa et al. (2005). The data here is an extract from their result.

\begin{tabular}{cc}
\hline Station code & Direction of "North" of seismometer \\
\hline FKO006 & N352.4 $\mathrm{E}$ \\
FKO007 & $\mathrm{N} 342.0^{\circ} \mathrm{E}$ \\
SAG001 & $\mathrm{N} 4.1^{\circ} \mathrm{E}$ \\
SAG005 & $\mathrm{N} 9.9^{\circ} \mathrm{E}$ \\
FKOH02 & $\mathrm{N} 3.7^{\circ} \mathrm{E}$ \\
\hline
\end{tabular}

Table 4. Station correction of $S-P$ time.

\begin{tabular}{cc}
\hline Station code & Station correction of $S$ - $P$ time $(\mathrm{s})$ \\
\hline FKO006 & 0.26 \\
FKO007 & 0.02 \\
NGS021 & -0.82 \\
SAG001 & 0.11 \\
SAG005 & -0.28 \\
FKOH02 & 0.26 \\
FKOH03 & -0.06 \\
FKOH09 & 0.01 \\
SAGH02 & -0.17 \\
SAGH03 & -0.33 \\
YMGH08 & -0.37
\end{tabular}

ring to the following three data items. 1) PS-logging data at K-NET and KiK-net station distributed on the NIED web page, 2) Bedrock depth model by Nakamichi and Kawase (2002), and 3) Bedrock depth model deduced from gravity anomaly data by Geological Survey of Japan, AIST (2005). We add a sedimentary layer structure with the bedrock depth given above, keeping the thickness ratio of each sedimentary layer in Nakamichi and Kawase (2002). We then confirm the model by forward modeling of an aftershock. Information 2) and 3) are both based on gravity anomaly data, and absolute depths may not be correct. Therefore, when we do not obtain bedrock depth information from 1) because the PS-logging does not reach the bedrock depth, we calculate synthetic waveforms by varying the bedrock depth assumed from 2) or 3 ) to find the best depth. Table 2 shows the bedrock depth.

$Q$-values for the sedimentary layers are assumed following Nakamichi and Kawase (2002). Below the seismological basement, we assum $(Q p, Q s)=(500,250)$ for the top of the seismological basement and $(Q p, Q s)=$ $(1000,500)$ for the deeper part.

\subsection{Data and methods}

Strong motion data from 11 stations of K-NET and KiKnet whose epicenter distances are less than $110 \mathrm{~km}$ are used for the analysis. Their locations are shown in Fig. 1. The observed acceleration records are corrected for the orientation of horizontal components using the orientation measured by Morikawa et al. (2005) (Table 3), integrated into velocity, and bandpass filtered between $0.1-1.0 \mathrm{~Hz}$. We invert 15 seconds of the $S$-wave portion from $1 \mathrm{~s}$ before $S$ wave arrival. As mentioned previously, it is difficult to identify arrivals of the first $S$-wave on the observed waveforms. We use the $S$ - $P$ time of the aftershocks which occurred close to the hypocenter of the mainshock to estimate the $S$-wave onset time on the mainshock waveforms. We select 

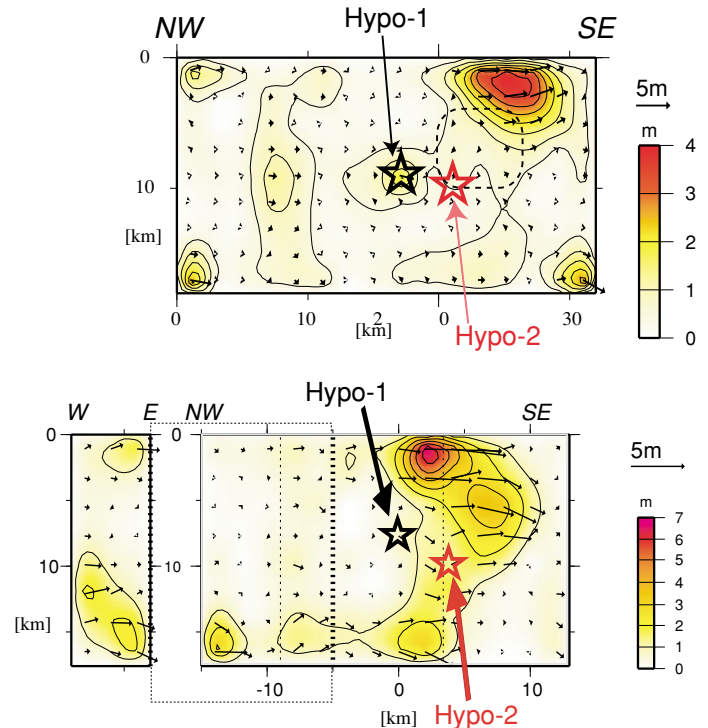

Fig. 6. Upper: Distributions of coseismic slip obtained for the 2005 West Off Fukuoka Prefecture earthquake. The star indicates the hypocenter. Arrows show the amplitude and directions of slip. Area surrounded by dashed line is found responsible for the generation of $1 \mathrm{~s}$ pulse observed at stations to the southeast of the fault. Contour interval is $0.5 \mathrm{~m}$. Lower: Distributions of coseismic slip obtained for the 2000 Western Tottori Prefecture earthquake. Hypo-1 and Hypo-2 are the starting points for the initial rupture and main rupture, respectively.

two aftershocks within $2.5 \mathrm{~km}$ of the mainshock hypocenter (Table 1, 3/21 and 3/24) and read the $S$ - $P$ time on the aftershock waveforms; on the other hand, we calculate theoretical $S$ - $P$ time for the aftershocks, assuming a crustal structure model (Ukawa et al., 1984). The difference between the observed and theoretical $S$ - $P$ time is due to the shallow velocity structure at each station. We call it "station correction for $S$ - $P$ time". Assuming the ray path from these aftershocks and from the hypocenter of the mainshock to be similar to each other, we are able to estimate the $S$-wave onset time for initial rupture phase of the mainshock by

$$
T_{S 1}=T_{P 1}+T_{S-P_{\text {theo }}}+C_{S-P} .
$$

$C_{S-P}$, station correction of $S-P$ time for each station is listed in Table 4. For stations where both of two aftershock records are available, we take the average of the two estimations.

Theoretical Green's functions are calculated using the discrete wavenumber method (Bouchon, 1981) and the Reflection/Transmission coefficient matrix method (Kennett, 1983) using the stratified media mentioned in the previous section. To represent rupture propagation in each subfault, the moving dislocation effect is considered following Sekiguchi et al. (2002). We use the multi-time-window linear waveform inversion procedure (e.g., Hartzell and Heaton, 1983) in which the moment-release distribution is discretized in both space and time. For discretization in space, we divide the fault plane into 16 in the strike direction and into 9 in the down-dip direction (making a total of 144 subfaults of size $2 \mathrm{~km} \times 2 \mathrm{~km}$ ). We use 6 smoothed ramp functions of 1.0 -second duration at 0.5 seconds interval to represent the slip history of each subfault. The triggering front of the first-time-window (first ramp func-

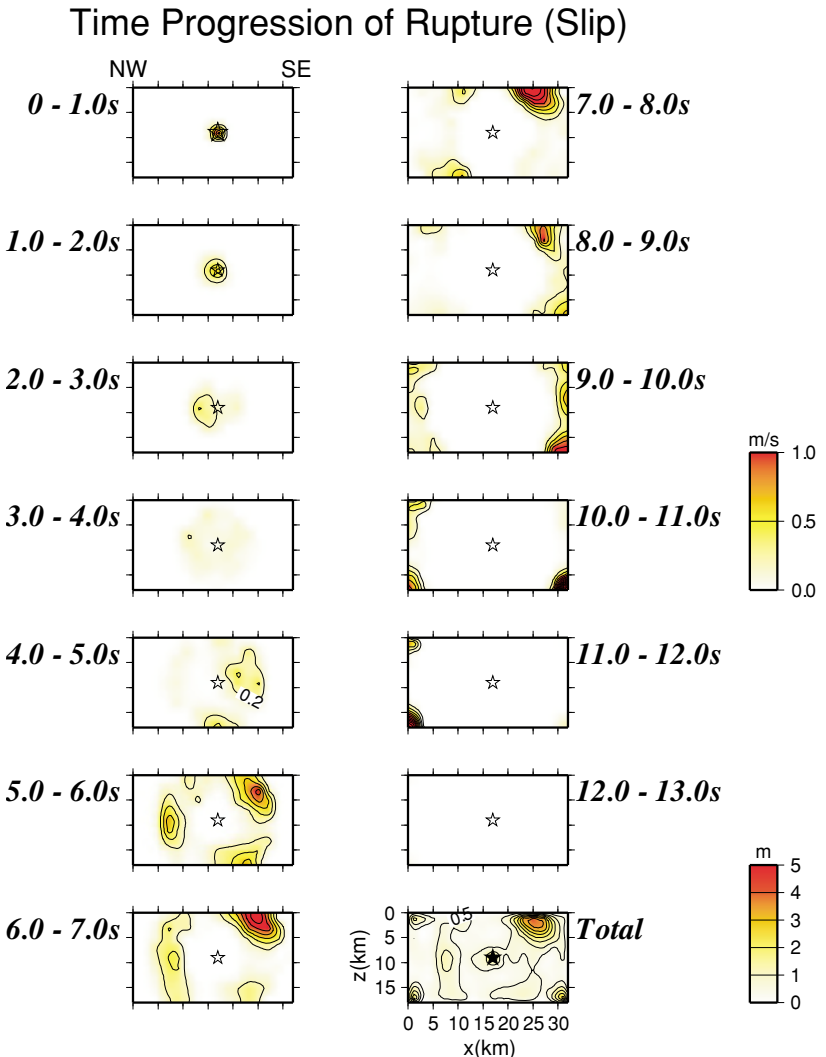

Fig. 7. Snapshots of the rupture progression every second. Contour interval of slip velocity is $0.2 \mathrm{~m} / \mathrm{s}$. The star indicates the hypocenter. Numbers at the side of each flame show the time after the start of the rupture.

tion) propagates at a constant velocity, and the multi-timewindow analysis allows variable rupture velocity and slip duration in inverted rupture models by weighted time windows. To suppress instability or excessive complexity, a smoothing constraint to reduce differences in moment release values close in space and time is introduced. Nonnegative constraints (Lawson and Hanson, 1974) to limit the rake-angle variation are also adopted. The rake angles are allowed to vary within $45^{\circ}$ centered at $-11^{\circ}$, which is the rake angle of the moment tensor solution of F-net. We perform numerous inversions by changing the first-timewindow triggering velocity at $0.1 \mathrm{~km} / \mathrm{s}$ intervals and the smoothing strength. Appropriate values for the smoothing strength and the propagation velocity of the first-timewindow triggering are selected based on ABIC (Akaike's Bayesian Information Criterion; Akaike, 1980) and the residual of the waveform fitting, respectively.

\subsection{Inversion results and discussions}

In the total slip distribution, we can see a large asperity in the southeast and shallow part of the fault plane. The asperity is about $8 \mathrm{~km} \times 6 \mathrm{~km}$, and the slip on the asperity is 3 to $4 \mathrm{~m}$ (Fig. 6). The slip vectors indicate an almost pure left-lateral strike slip fault mechanism. Time progression of the rupture (Fig. 7) shows that the rupture started with a high slip rate at the hypocenter, declined to a low slip rate from 2 to $4 \mathrm{~s}$ after the start of the rupture, and switched to a high slip rate in the southeast and shallower part of the fault (asperity area) about $5 \mathrm{~s}$ after the rupture initiation. 


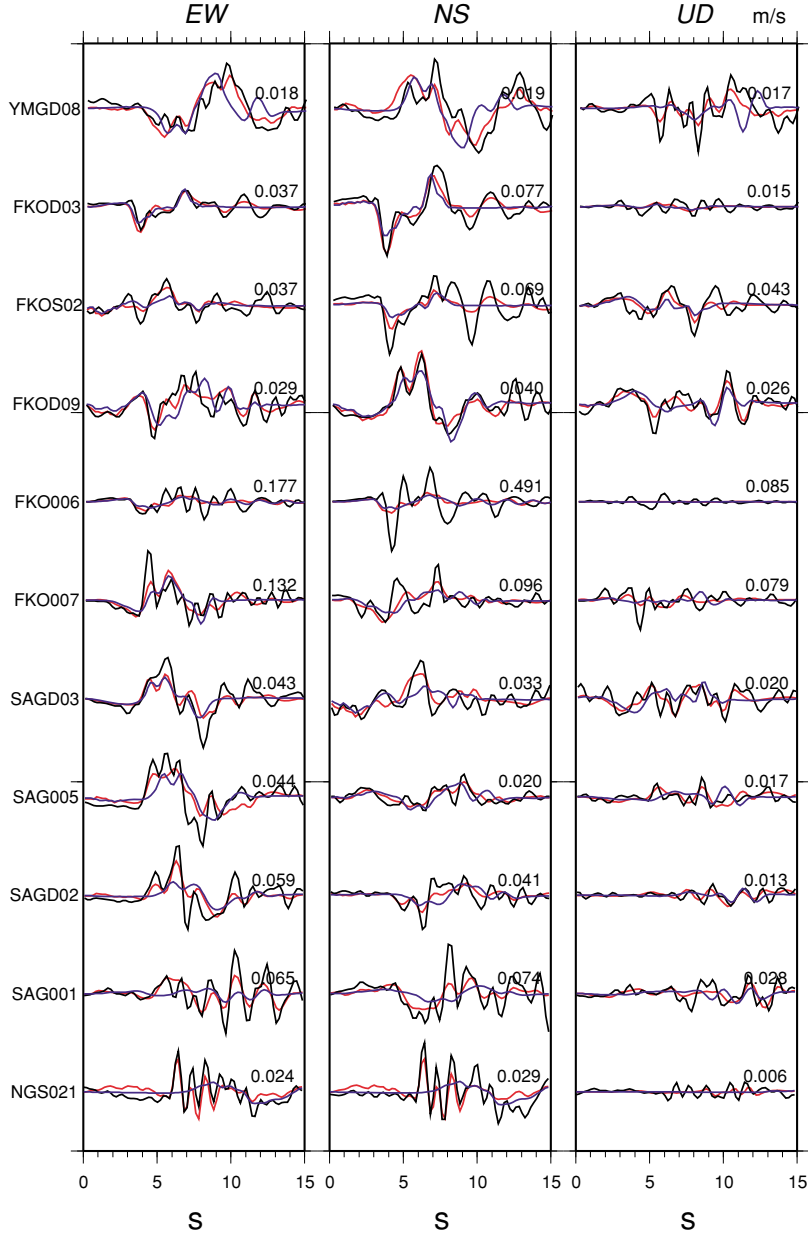

Fig. 8. Comparison between observed and synthetic velocity waveforms. The black lines are the observed waveforms. The red lines are the synthetic waveforms from slip over the whole fault plane. The blue lines are the synthetics from slip on the asperity (from 4 to $14 \mathrm{~km}$ in the strike direction, and from 0 to $8 \mathrm{~km}$ in the downdip direction in Fig. 5). The maximum amplitude of each component of the observed waveforms is given on the right shoulder of each trace in $\mathrm{m} / \mathrm{s}$. Each trace is normalized by the maximum amplitude recorded at each station.

Total moment release is $1.16 \times 10^{19} \mathrm{Nm}(\mathrm{Mw} 6.6)$ and the propagation velocity of the first time window triggering is found to be $2.1 \mathrm{~km} / \mathrm{s}$ (about $60 \%$ of the $S$-wave velocity in the source area).

Source process models by the waveform inversion are also proposed by Asano and Iwata (2006) and Horikawa (2006) in this issue. Three models obtained similar features; the rupture expanded toward southeast, an asperity in the southeast and shallow part of the fault plane. The propagation velocity of the first time window triggering is the same for Asano and Iwata (2006) and our model. The difference between our model and the others is that the others found another asperity below the shallow asperity. There is no remarkable slip there in our model.

Synthetics from the estimated rupture process are compared to data in Fig. 8. Red lines are the synthetics from the slip over the whole fault plane. Overall matching of the waveforms is good, but the $1 \mathrm{~s}$ pulses at some stations, e.g., FKO006, FKO007 and FKOH02, are not well recovered. The asperity portion explains most of the large-amplitude

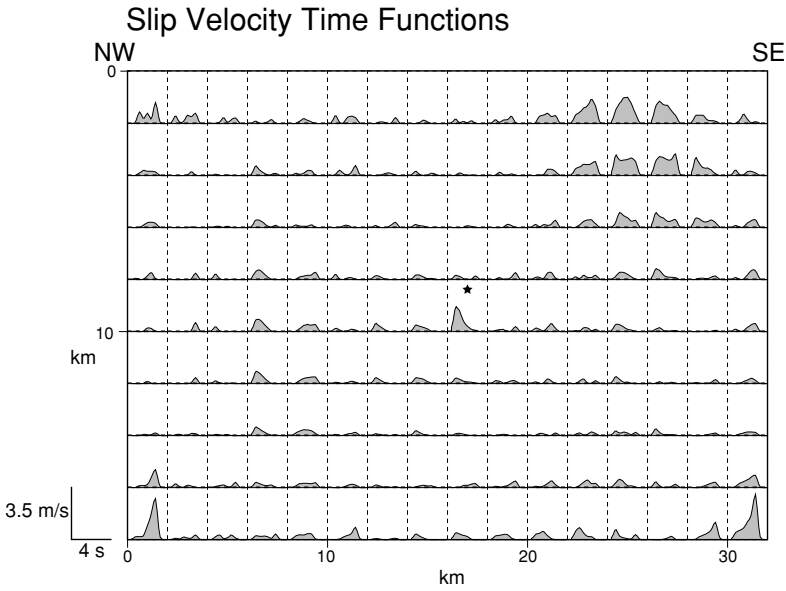

Fig. 9. Slip velocity time function on each subfault. The slip velocity function denoted by a star is one at the hypocenter subfault.

signals in the waveforms (blue lines in Fig. 8), except at station NGS021 to the northwest of the hypocenter.

Hypo-2, the initiation of the main rupture mapped in Chapter 2, falls onto an area between Hypo-1 and the asperity where the slip is quite small compared to that in the asperity (Fig. 6, upper). We expected to see an event with a high moment release rate in a short time there corresponding to the $1 \mathrm{~s}$ pulse seen in the observed waveform, but we do not find such event neither in slip time functions (Fig. 9) nor in the time progression of the rupture (Fig. 7). Having examined the contribution of slip on each portion of the fault plane, we find that the slips over an area from Hypo-2 to the bottom of the asperity (indicated by dashed line in Fig. 6) are responsible for the generation of the $1 \mathrm{~s}$ pulse. This suggests that the transition from initial rupture to main rupture was not an abrupt event but a gradual one in space and in time. Comparing the $1 \mathrm{~s}$ pulse in the observations, the pulse width of the " $1 \mathrm{~s}$ pulse" is $0.9-1.0 \mathrm{~s}$ at stations to the southeast of the fault, becomes larger as we go towards west, and is $1.2-1.5 \mathrm{~s}$ at stations to the south and to the southwest of the fault. We believe that the directivity effect due to rupture propagation toward the southeast play an important role in generating the pulse.

At stations FKO006, FKO007 and FKOH02-S, the 1 $\mathrm{s}$ pulses are underestimated. Additionally, for station FKO006, NS/EW amplitude ratio of the $1 \mathrm{~s}$ pulse portion shows a large discrepancy between observation and synthetics, and the discrepancy gets smaller in the lower frequency range. In searching for a reason for the former issue, we suspect that the strike angle of the fault plane model was inappropriate. We vary the strike angle within the possible range suggested by the aftershock distribution ( \pm 5 degrees) but we do not improve the fit of the $1 \mathrm{~s}$ pulse. On the latter issue, we suspect that the effect of a shallow velocity structure for station FKO006 is responsible for rotation of the dominant orientation of ground motion in high frequency range. We vary the bedrock depth, but find it difficult to explain this phenomenon with a layered structure model based on the present assumption of a fault plane mechanism.

The feature of this rupture process model is similar to that of the 2000 Western Tottori Prefecture earthquake (Mw 
6.8), a strike slip event that occurred in the San'in region, southwest Japan. In the Tottori-ken Seibu earthquake, an asperity of about $10 \mathrm{~km} \times 8 \mathrm{~km}$ was triggered at a point about $5 \mathrm{~km}$ from the hypocenter (Hypo-2 in Fig. 6, lower) about $3 \mathrm{~s}$ after the start of the earthquake, and $2-3 \mathrm{~s}$ of the initial rupture phase was observed (Sekiguchi and Iwata, submitted manuscript). The pulses generated from Fukuoka and Tottori earthquakes are also similar.

\section{Conclusions}

We investigated the rupture process of the 2005 West Off Fukuoka Prefecture earthquake by examining the local strong motion waveforms and by multi-time-window linear waveform inversion. An initial few seconds' portion of relatively small amplitude is clearly seen in the observed waveforms. The duration of this initial rupture phase shows spatially systematic variation, which indicates that the rupture mode switched from a low energy-release mode to a high energy-release mode in an area about $4 \mathrm{~km}$ to the southeast of the hypocenter. Stress drop during the initial rupture phase is estimated to be in the same order of those of moderate size aftershocks, which indicates that the initial rupture does not differ from ordinary dynamic rupture of earthquakes.

The inverted source process model shows that the rupture starts with a high slip rate at the hypocenter, decline to a low slip rate for a few seconds, then return to a high slip rate in the southeast and shallower part of the hypocenter. There found single asperity, of which size is about $8 \mathrm{~km} \times$ $6 \mathrm{~km}$, with its center located $8 \mathrm{~km}$ to the southeast and $6 \mathrm{~km}$ above the hypocenter. This asperity explains most of the large-amplitude signals in the waveforms.

Acknowledgments. We are deeply grateful to Dr. Hiroshi Takenaka and another anonymous referee for detailed comments and corrections. This work is conducted under the auspices of the "National Strong Motion Mapping Project" of the National Research Institute for Earth Science and Disaster Prevention, Japan. GMT (Wessel and Smith, 1995) was used to make the figures.

\section{References}

Akaike, H., Likelihood and the Bayes procedure, in Bayesian Statics, edited by J. M. Bernardo, M. H. DeGroot, D. V. Lindley, and A. F. M. Smith, University Press, Valencia, Spain, 1980.

Aoi, S., K. Obara, S. Hori, K. Kasahara, and Y. Okada, New strong-motion observation network: KiK-net, EOS. Trans. Am. Geophys. Union, 329, 2000.

Asano, K. and T. Iwata, Source process and near-source ground motions of the 2005 West Off Fukuoka Prefecture earthquake, Earth Planets Space, 58, this issue, 93-98, 2006.

Beroza, G. C. and W. L. Ellsworth, Properties of the seismic nucleation phase, Tectonophysics, 261, 209-227, 1996.

Bouchon, M., A simple method to calculate Green's function for elastic layered media, Bull. Seis. Soc. Am., 71, 959-971, 1981.

Eshelby, J. D., The determination of the elastic field of an ellipsoidal inclusion, and related problems, Proc. Royal Soc. London, A241, 376396, 1957.

Fukuyama, E., M. Ishida, S. Hori, S. Sekiguchi, and S. Watada, Broadband seismic observation conducted under the FREESIA Project, Rep. Nat'l. Res. Inst. Earth Sci. Disas. Prev., 57, 23-31, 1996 (in Japanese).

Geological Survey of Japan, AIST, Gravity field around the source region of the 2005 west off Fukuoka earthquake, Report of the coordinating committee for earthquake prediction, 74, 507-509, Geographical Survey Institute, 2005a (in Japanese).

Geological Survey of Japan, AIST, Seismic profiles acquired in 1985 by Geological Survey of Japan, in aftershock area of 2005 Fukuoka earthquake, 74, 507-509, Geographical Survey Institute, 2005b (in Japanese).

Hartzell, S. H. and T. Heaton, Inversion of strong ground motion and teleseismic waveform data for the fault rupture history of the 1979 Imperial Valley, California, earthquake, Bull. Seis. Soc. Am., 73, 15531583, 1983.

Horikawa, H., Rupture process of the 2005 West Off Fukuoka Prefecture, Japan, earthquake, Earth Planets Space, 58, this issue, 87-92, 2006.

Hydrographic and Oceanographic Department, Japan Coast Guard, An interim report of surveys of seabed in the source region of the west off Fukuoka prefecture earthquake, Report of the coordinating committee for earthquake prediction, 74, 501-504, Geographical Survey Institute, 2005 (in Japanese).

Karakida, Y., S. Tomita, S. Shimoyama, and K. Chijiwa, 1:50,000 Geologic map "Fukuoka", 1994 (in Japanese).

Kennett, B. L. N., Seismic Wave Propagation in Stratified Media, Cambridge University Press, Cambridge, 1983.

Kinoshita, S., Kyoshin net (k-net), Seism. Res. Lett., 69, 309-332, 1998.

Lawson, C. and R. Hanson, Solving Least Squares Problems, 340 pp., Prentice-Hall, Inc., New Jersey, 1974.

Mori, J. and H. Kanamori, Initial rupture of earthquakes in the 1995 Ridgecrest, California sequence, Geophys. Res. Lett., 23, 2437-2440, 1996.

Morikawa, N., S. Adachi, H. Takenaka, T. Kunugi, and H. Fujiwara, Analysis of strong motion recrods and station investigation of K-NET and KiK-net, JSPS report, 2005 (in Japanese).

Nakamichi, S. and H. Kawase, Broad band strong motion prediction by hybrid method considering 3D velocity structure in Fukuoka city, Journal of structural and construction engineering: transactions of AIJ, 560, 83-91, 2002 (in Japanese).

Obara,K., K. Kasahara, S. Hori, and Y. Okada, A densely distributed highsensitivity seismograph network in Japan: Hi-net by National Research Institute for Earth Science and Disaster Prevention, Review of Scientific Instruments, 76, 021301-doi:10.1063/1.1854197, 2005.

Sekiguchi, H. and T. Iwata, Rupture Process of the 2000 Tottori-ken Seibu, Japan, earthquake by joint inversion of strong motion and geodetic data, submitted to Bull. Seism. Soc. Am.

Sekiguchi, H., K. Irikura, and T. Iwata, Source inversion for estimating continuous slip distribution on the fault-Introduction of Green's functions convolved with a correction function to give moving dislocation effects in subfaults, Geophys. J. Int., 150, 377-391, 2002.

Takenaka, H., T. Nakamura, Y. Yamamoto, G. Toyokuni, and H. Kawase, Precise location of the fault plane and the onset of the main rupture of the 2005 West Off Fukuoka Prefecture earthquake, Earth Planets Space, 58, this issue, 75-80, 2006.

Ukawa, M., M. Ishida, S. Matsumura, and K. Kasahara, Hypocenter determination method of the Kanto-Tokai observational network for microearthquakes, Rep. Nat'l. Res. Inst. Earth Sci. Disas. Prev., 53, 1-88, 1984 (in Japanese).

Wessel, P. and W. Smith, New version of the generic mapping tools, EOS., Trans. Am. Geophys. Un.,76, 445-446, 1995.

H. Sekiguchi (e-mail: Haruko.Sekiguchi@aist.go.jp), S. Aoi, R. Honda, N. Morikawa, T. Kunugi, and H. Fujiwara 